\title{
Intravitreal Ranibizumab Therapy for Diabetic Macular Edema in Routine Practice: Two-Year Real- Life Data from a Non-interventional, Multicenter Study in Germany
}

\author{
Focke Ziemssen (D) - Joachim Wachtlin · Laura Kuehlewein · Maria-Andreea Gamulescu • \\ Thomas Bertelmann · Nikolaus Feucht · Jessica Voegeler • Mirja Koch • Sandra Liakopoulos • \\ Steffen Schmitz-Valckenberg · Georg Spital · for the OCEAN study group
}

Received: August 21, 2018 / Published online: October 4, 2018

(C) The Author(s) 2018

\section{ABSTRACT}

Introduction: The prospective, non-interventional OCEAN study examined the use of intravitreal ranibizumab injections for the treatment of diabetic macular oedema (DME) in a real-world setting in Germany.

Methods: Adults with DME receiving $\geq 1$ ranibizumab (0.5 $\mathrm{mg})$ injections were

Enhanced Digital Features To view enhanced digital features for this article go to https://doi.org/10.6084/ m9.figshare.7077746.

Electronic supplementary material The online version of this article (https://doi.org/10.1007/s13300018-0513-2) contains supplementary material, which is available to authorized users.

F. Ziemssen $(\bowtie) \cdot$ L. Kuehlewein

Centre for Ophthalmology, Eberhard-Karls-

University Tuebingen, Tuebingen, Germany

e-mail: focke.ziemssen@med.uni-tuebingen.de

J. Wachtlin

St. Gertrauden Krankenhaus, Berlin, Germany

J. Wachtlin

Medizinische Hochschule Brandenburg Theodor

Fontane, Neuruppin, Germany

M.-A. Gamulescu

University Eye Hospital, Regensburg, Germany

T. Bertelmann

Artemis Eye Clinic, Dillenburg, Dillenburg,

Germany recruited by 250 ophthalmologists. Best-corrected visual acuity (VA) testing, imaging and treatments were performed according to the investigators' routine practice and documented over 24 months.

Results: The full analysis set included 1226 participants. Mean baseline VA was 60.6 [95\% CI: 59.7; 61.5] Early Treatment Diabetic Retinopathy Study letters. VA improved by $\geq 15$ letters in $21.5 \%$ and $23.5 \%$ of the participants at 12 months and 24 months, respectively. They received a mean number of 4.42 [95\% CI: 4.30; 4.54] injections in the first year and 5.52 [95\% CI: 5.32; 5.73] injections over 24 months, which was markedly lower than in clinical trials. Only $33.4 \%$ of the participants received an upload with four initial monthly

\author{
T. Bertelmann \\ Department of Ophthalmology, University Medical \\ Center Goettingen, Goettingen, Germany \\ N. Feucht \\ Klinikum Rechts der Isar, Technical University, \\ Munich, Germany \\ J. Voegeler · M. Koch \\ Novartis Pharma GmbH, Nuremberg, Germany \\ S. Liakopoulos \\ Centre for Ophthalmology, University Hospital of \\ Cologne, Cologne, Germany
}


injections as recommended by the German ophthalmologic societies. Time-to-event analyses that account for missing data inherent to a non-interventional study design demonstrated that participants receiving $\geq 7$ injections in the first year had a faster response, but the duration of the response was shorter compared to the subgroups receiving 1-3 and 4-6 injections. Serious adverse events were reported for $143 / 1250$ (11.4\%) participants in the safety population.

Conclusion: Under-treatment is a major problem of DME anti- vascular endothelial growth factor therapy under real life conditions. Despite fewer injections given compared to randomised controlled trials with a consequently reduced overall mean visual gain, a profound functional improvement ( $\geq 15$ letters) was achieved over 2 years in $23.5 \%$ of eyes with DME.

Trial Registration Number: NCT02194803, ClinicalTrials.gov.

Funding: Novartis Pharma GmbH, Nuremberg, Germany.

Keywords: Diabetic macular edema; Observational study; Ranibizumab; Treatment outcome; Vascular endothelial growth factor A

\section{INTRODUCTION}

Diabetic macular edema (DME) currently affects approximately 20 million people worldwide [1]. At the present time intravitreal anti-vascular endothelial growth factor (VEGF) therapy is the standard of care [1-6]. A network meta-analysis that included 24 clinical studies with 6007 participants confirmed that anti-VEGF therapy offers greater improvement in visual acuity (VA) than does laser photocoagulation, with an acceptable safety profile [4]. These

S. Schmitz-Valckenberg

Department of Ophthalmology, University of Bonn,

Bonn, Germany

G. Spital

Augenzentrum am St. Franziskus Hospital,

Muenster, Germany improvements usually occur within 1 year and can be sustained for up to 5 years $[2,3,7]$.

For the treatment of visual impairment due to DME, German medical societies [8] recommend an initial upload of four anti-VEGF injections at monthly intervals, followed by two injections monthly and then by a single monthly injection if further treatment is needed. Monthly assessments of retinal thickness by optical coherence tomography (OCT) and VA should guide re-treatment (Electronic Supplementary Material [ESM] Fig. S1). These societies also recommend performing fluorescein angiography (FA) and OCT before initiating anti-VEGF therapy to confirm DME as the treatment indication and to detect ischemic maculopathy or permanent damage to the retina, both of which predict poor response to treatment [8].

In the clinical trials reported to date, an average of 7-12 injections were administered in the first year and three to six injections in the second year $[2,3,9,10]$. Adhering to this schedule can be difficult outside of clinical trials, which may lead to under-treatment [4]. Moreover, older patients and a higher frequency of comorbidities in a real-world setting may further reduce adherence to monitoring and therapy and impair the effectiveness of ranibizumab for the management of DME [11, 12]. The effects of these factors merit evaluation, but such evaluations have so far been largely undocumented or restricted to retrospective data [13-15].

Therefore, we have prospectively examined the effectiveness, treatment, monitoring and safety of ranibizumab $(0.5 \mathrm{mg})$ injections in individuals with DME in Germany in the realworld, non-interventional OCEAN (Observation of treatment patterns with LuCEntis and reallife ophthalmic monitoring, including optional OCT in Approved iNdications) study.

\section{METHODS}

\section{Study Design}

The prospective, multicenter, non-interventional OCEAN study examined the use of 
intravitreal ranibizumab in adults with neovascular, exudative or edematous eye diseases, under real-world conditions in Germany [11]. One eye per patient was included. The OCEAN study was approved by the ethics committee of the Eberhard-Karls-University, Tübingen, Germany. All procedures performed in studies involving human participants were in accordance with the ethical standards of the institutional and/or national research committee and with the 1964 Helsinki declaration and its later amendments or comparable ethical standards. Informed consent was obtained from all individual participants included in the study.

Here we describe the subpopulation treated with ranibizumab for visual impairment due to DME, accounting for $21.6 \%$ of the OCEAN safety population (1250 of 5781 participants). Data were collected between December 2011 and December 2016.

\section{Participants and Study Centers}

The aims of the OCEAN study [11] were to provide a representative picture of ophthalmologists in Germany and of the individuals treated with ranibizumab. Exclusion criteria were contra-indications based on the Summary of Product Characteristics, intravitreal antiVEGF treatment of the study eye in the 3 months prior to enrolment or previous intravitreal steroid treatment. The subpopulation described here included only patients with diabetes mellitus and center-involved DME as the primary indication for ranibizumab. Participants with DME were recruited by 250 of the 369 OCEAN study centers, among which were 49 general ophthalmology practices (of the 4735 such practices in Germany) and 201 retina specialist centers (of the approximately 1200 such centers in Germany).

\section{Evaluation}

Data were collected prospectively by the treating physicians. Demographics, clinical characteristics, previous ranibizumab injections, VA and results from OCT and FA were recorded at baseline. At subsequent visits, the date, whether an injection was administered or not (plus reason for decision), VA and OCT measurements and any adverse events (AEs) were captured along with premature discontinuation of treatment or documentation.

Values for best-corrected VA were converted to logarithm of minimum angle of resolution (LogMAR) values and Early Treatment Diabetic Retinopathy Study (ETDRS) letters [16].

AEs were reported according to World Health Organization guidelines [17].

\section{Data Analysis}

The safety population includes all enrolled participants receiving $\geq 1$ ranibizumab injection within OCEAN with at least one safety assessment. The full analysis set (FAS) includes all eligible participants. The potential influence of baseline VA was delineated by defining three subpopulations based on approximate tertiles of baseline VA $(<55$ ETDRS letters, 55-68 letters, $>68$ letters). Further subgroup analyses were conducted stratified by sex, pre-treatment status (treatment-naïve: no documented previous intravitreal anti-VEGF treatment and $\leq 90$ days between diagnosis and first injection within OCEAN; pre-treated: received anti-VEGF treatment $>3$ months before study entry; remaining participants were considered to be possibly pretreated) and number of injections in the first year.

Data analysis was performed using $\mathrm{SAS}^{\circledR}$ software, version 9.4 (SAS Institute Inc., Cary, NC, USA). Data are presented descriptively as the mean with the $95 \%$ confidence interval (95\% CI), the mean with the standard deviation or the percentage of patients. To account for missing data inherent to the non-interventional design of the study $[11,18]$, time-to-discontinuation, time-to-response (to first improvement of $\geq 15$ ETDRS letters from baseline) and duration-of-response (time from first improvement of $\geq 15$ ETDRS letters to first time point of losing this improvement) were analyzed using Kaplan-Meier estimates. 


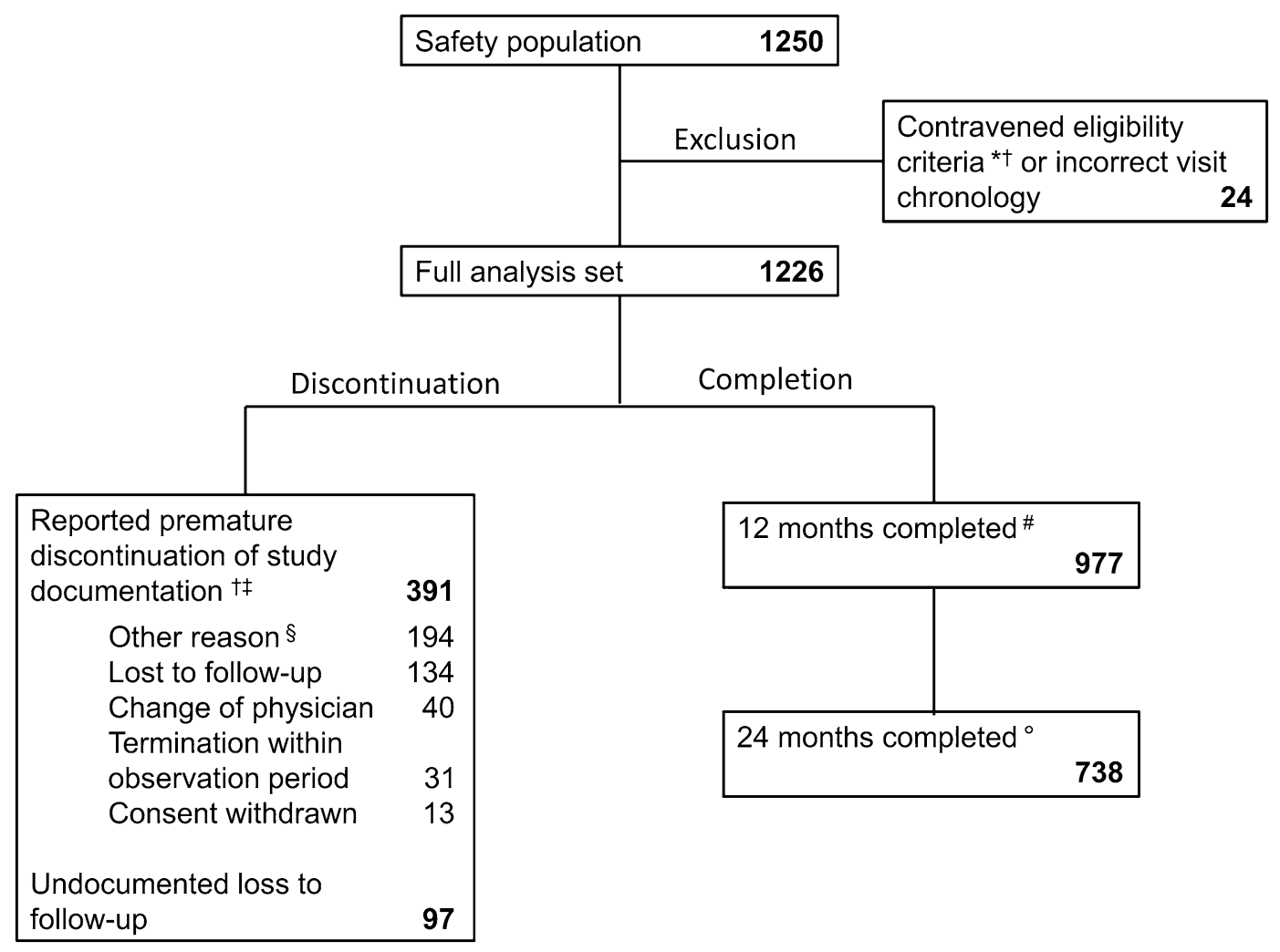

Fig. 1 Flow chart of disposition of patients with diabetic macular edema (DME) in the OCEAN study. Asterisk refers to reasons for exclusion from the full analysis set: pre-treatment of study eye with intravitreal anti-vascular endothelial growth factor (VEGF) within the last 3 months and/or pre-treatment with intravitreal steroids in the past $(n=12)$; not documented that DME was present and that ranibizumab treatment was medically indicated and planned $(n=7)$; pre-treatment with ranibizumab within the last 3 months $(n=4)$; and major, unresolvable errors in the visit chronology $(n=1)$. Dagger

\section{RESULTS}

\section{Study Population}

After verifying eligibility in 1250 participants (safety population), data from 1226 participants (774 treatment-naïve, 181 pre-treated, 301 possibly pre-treated) were included in the effectiveness analysis (FAS) (Fig. 1).

The mean baseline age was 67.6 years, $57.5 \%$ of the population were men and $77.4 \%$ had type 2 diabetes mellitus (Table 1 ). denotes multiple responses possible. Double dagger denotes that documentation discontinued before month 24. Double $S$ denotes 'Other reason' for premature discontinuation of documentation and was most frequently specified as change to 'other anti-VEGF medication' $(n=49)$, change to aflibercept $(n=25)$ or change to bevacizumab $(n=19)$. Hashtag denotes the 947 participants with a documented visit at month 12 and the 30 participants who did not have a visit at month 12 but did have a later documented visit. Degree symbol denotes participants with a documented visit at month 24

\section{Follow-up, Treatment and Monitoring}

Of the 1226 participants in the FAS, 977 (79.7\%) completed the first 12 months of the study and 738 (60.2\%) completed 24 months (Fig. 1). Premature study discontinuation was documented for 391 participants (31.9\%), mainly due to loss to follow-up (134 participants) or "other reasons" (194 participants).

The mean observational period was 507.1 (95\% CI 492.8; 521.3) days.

The study participants received on average 4.42 (95\% CI 4.30; 4.54) ranibizumab injections 
Table 1 Baseline characteristics of study participants with diabetic macular edema (full analysis set, $n=1226$ )

\begin{tabular}{|c|c|}
\hline Parameter & Values $^{\mathrm{a}}$ \\
\hline Age (years) ${ }^{b}$ & $67.6 \pm 10.8$ \\
\hline \multicolumn{2}{|l|}{ Gender } \\
\hline Men & $705(57.5 \%)$ \\
\hline Women & $515(42.0 \%)$ \\
\hline Missing & $6(0.5 \%)$ \\
\hline \multicolumn{2}{|l|}{ Anamnestic risk factors $^{c}$} \\
\hline Diabetes mellitus & $\begin{array}{l}1226 \\
(100.0 \%)\end{array}$ \\
\hline Type I & $118(9.6 \%)$ \\
\hline Type II & $949(77.4 \%)$ \\
\hline Unknown & $90(7.3 \%)$ \\
\hline Missing & $70(5.7 \%)$ \\
\hline Hypercholesterolemia & $184(15.0 \%)$ \\
\hline Neovascular disease of the other eye & $176(14.4 \%)$ \\
\hline Hyperlipidemia & $92(7.5 \%)$ \\
\hline Myocardial infarction & $84(6.9 \%)$ \\
\hline Family history of coronary artery disease & $69(5.6 \%)$ \\
\hline Apoplexy & $66(5.4 \%)$ \\
\hline Other thromboembolism event & $31(2.5 \%)$ \\
\hline Other metabolic dysfunction & $22(1.8 \%)$ \\
\hline Other risk factors & $339(27.7 \%)$ \\
\hline $\mathrm{HbAlc}(\mathrm{mmol} / \mathrm{mol})^{\mathrm{b}}$ & $58 \pm 13$ \\
\hline HbAlc $(\%)^{b}$ & $7.5 \pm 1.2$ \\
\hline \multicolumn{2}{|l|}{ HbAlc (categories) } \\
\hline$<64 \mathrm{mmol} / \mathrm{mol}(<8.0 \%)$ & $504(41.1 \%)$ \\
\hline$\geq 64 \mathrm{mmol} / \mathrm{mol}(\geq 8.0 \%)$ & $220(17.9 \%)$ \\
\hline Missing & $502(41.0 \%)$ \\
\hline \multicolumn{2}{|l|}{ OCT examination at baseline } \\
\hline Performed & $943(76.9 \%)$ \\
\hline Not performed & $276(22.5 \%)$ \\
\hline Missing & $7(0.6 \%)$ \\
\hline FA examination at baseline & \\
\hline
\end{tabular}

Table 1 continued

\begin{tabular}{ll}
\hline Parameter & Values $^{\mathbf{a}}$ \\
\hline Performed & $852(69.5 \%)$ \\
Not performed & $367(29.9 \%)$ \\
Missing & $7(0.6 \%)$ \\
OCT and FA examination at baseline & \\
OCT $=$ yes, FA $=$ yes & $654(53.3 \%)$ \\
OCT $=$ yes, FA $=$ no & $289(23.6 \%)$ \\
OCT $=$ no, FA $=$ yes & $198(16.2 \%)$ \\
OCT $=$ no, FA $=$ no & $77(6.3 \%)$ \\
Missing & $8(0.7 \%)$ \\
\hline
\end{tabular}

$F A$ Fluorescein angiography, $H b A l c$ glycated hemoglobin A1c, OCT optical coherence tomography

${ }^{a}$ Values are presented as the mean \pm standard deviation $(\mathrm{SD})$ or as a number with the percentage in parenthesis, as appropriate

b Data for some participants are missing: age (9 missing), HbAlc (502 missing)

${ }^{c}$ Multiple responses possible

in the first year and 5.52 (95\% CI 5.32; 5.73) injections over 24 months (Fig. 2). The number of injections did not differ by baseline VA (Table 2).

The longest interval was documented between the third and the fourth injection (Fig. 3). A four-injection upload was documented in $33.4 \%$ of the participants (Table 2).

Baseline OCT and FA examinations were reported for 77 and $70 \%$ of the participants, respectively (Table 1 ).

Over 12 and 24 months, a mean of 3.7 and 5.9 OCT examinations were performed in the FAS (Table 2). During the first year, 879 participants $(71.7 \%)$ had $\geq 2$ documented OCT examinations, $192(15.7 \%)$ had one OCT examination and 155 (12.6\%) did not have a OCT examination.

All participants received a mean of $8.6(95 \%$ CI 8.5 ; 8.8) and 14.2 (95\% CI 13.8; 14.7) VA examinations over 12 and 24 months, respectively. For the 738 participants completing 24 months of the study, 9.8 (95\% CI 9.6; 10.0) 

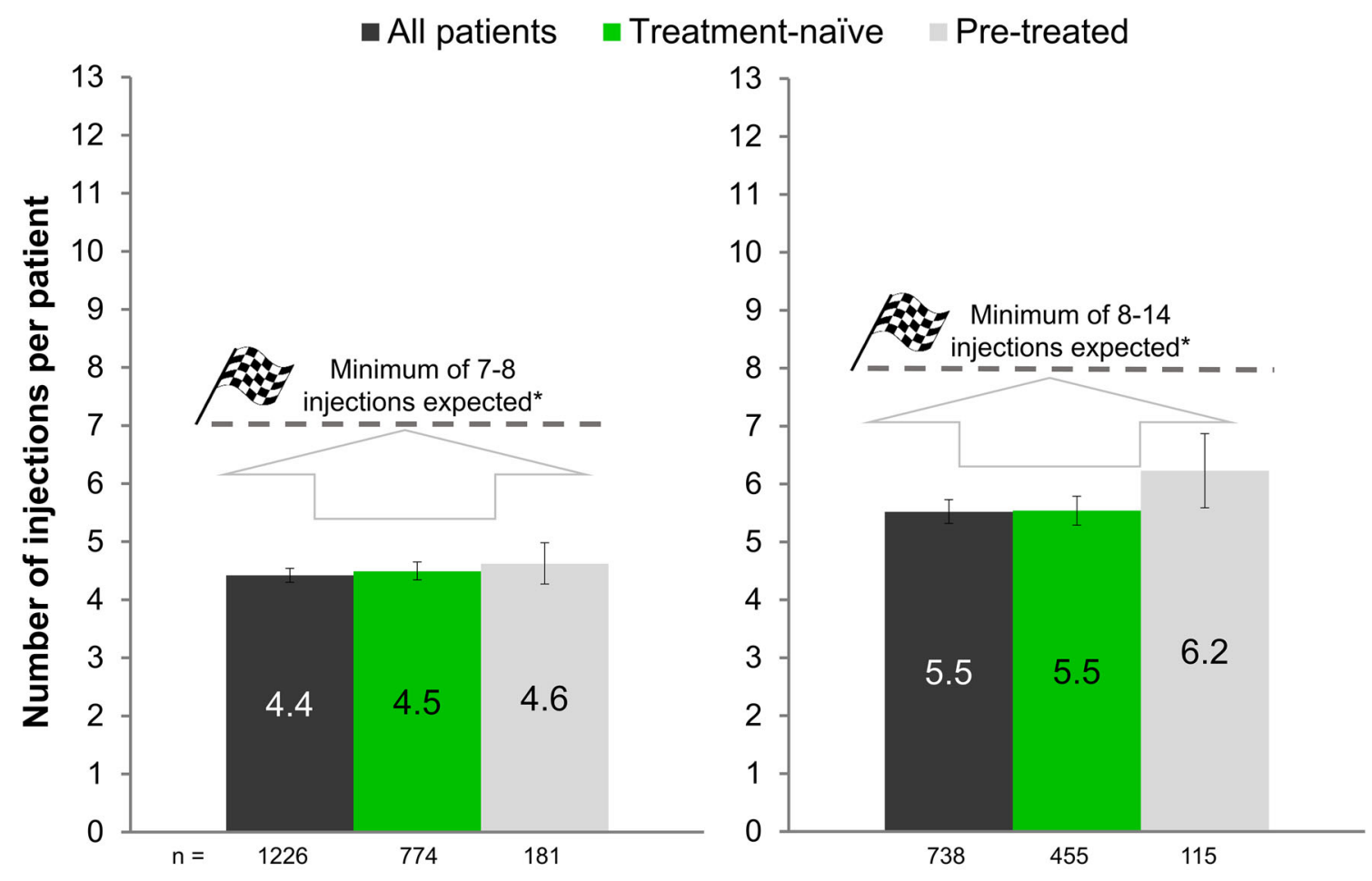

12 months

\section{Time period}

\section{4 months}

Fig. 2 Mean number of injections administered during the first 12 months and during the entire 24-month observational period of the OCEAN study compared to current German recommendations. Error bars depict confidence intervals. Asterisk denotes the expected number of injections is based on an initial upload of four injections at monthly intervals, followed by two additional monthly

and 18.3 (95\% CI 17.8; 18.7) VA examinations were documented, respectively.

\section{Visual Acuity}

The mean baseline VA was 60.6 (95\% CI 59.7; 61.5) ETDRS letters, with 464, 382 and 371 participants in the VA sub-groups of $>68$ ETDRS letters, 55-68 letters and $<55$ letters, respectively.

In the FAS, the mean VA was above baseline throughout the observation period (Table 3; ESM Table S1). VA improvement peaked initially at month $3(+4.9$ [95\% CI 4.1] 5.6 ETDRS letters), then remained relatively stable until injections as needed and then by single monthly injections as needed, as recommended by German medical societies. According to these recommendations it is expected that on average seven to eight injections are given during the first year and fewer than four injections are given in the second year $[2,8,30]$

month $12(+4.0$ ETDRS letters) and increased at the end of year 2, reaching + 5.2 ETDRS letters at month 24 (Fig. 4a; Table 3). In general, the discontinuation rate was constant (Fig. 4b).

At months 12 and $24,>20 \%$ of the participants gained $\geq 15$ ETDRS letters versus baseline, whereas VA deteriorated by $\geq 15$ letters in about $7 \%$ of participants (Table 3 ). The VA improvement was highest in participants with the lowest baseline VA and lowest in those with the highest baseline VA (ESM Fig. S2a). Baseline VA and changes from baseline (ESM Table S2, ESM Fig. S2b) were similar for participants given one to three or four to six ranibizumab injections, with a slightly greater improvement in 
Table 2 Treatment with ranibizumab for diabetic macular edema and monitoring by optical coherence tomography in the OCEAN study (full analysis set, $n=1226$ )

\begin{tabular}{|c|c|c|c|c|c|c|}
\hline \multirow[t]{2}{*}{ Parameter } & \multicolumn{2}{|c|}{ All participants } & \multicolumn{2}{|c|}{ Treatment-naïve } & \multicolumn{2}{|c|}{ Pre-treated } \\
\hline & $\bar{n}$ & Values $^{\mathbf{a}}$ & $\bar{n}$ & Values $^{\mathbf{a}}$ & $n$ & Values $^{\mathbf{a}}$ \\
\hline \multicolumn{7}{|c|}{ All participants, including those who discontinued prematurely } \\
\hline \multicolumn{7}{|c|}{ Number of injections in the first year (to month 12), by baseline VA ${ }^{b}$ in ETDRS letters } \\
\hline$<55$ Letters & 371 & $4.52[4.29 ; 4.74]$ & 217 & $4.61[4.30 ; 4.91]$ & 53 & $4.87[4.19 ; 5.55]$ \\
\hline 55-68 Letters & 382 & $4.26[4.05 ; 4.47]$ & 241 & $4.33[4.06 ; 4.60]$ & 55 & $4.24[3.62 ; 4.85]$ \\
\hline$>68$ Letters & 464 & $4.50[4.29 ; 4.71]$ & 309 & $4.56[4.31 ; 4.82]$ & 72 & $4.79[4.21 ; 5.37]$ \\
\hline \multicolumn{7}{|c|}{ Number of injections over the observational period (to month 24), by baseline VA ${ }^{\mathrm{b}}$ in ETDRS letters } \\
\hline$<55$ Letters & 371 & $5.62[5.25 ; 5.99]$ & 217 & $5.72[5.22 ; 6.21]$ & 53 & $6.32[5.15 ; 7.49]$ \\
\hline 55-68 Letters & 382 & $5.34[4.99 ; 5.69]$ & 241 & $5.30[4.86 ; 5.73]$ & 55 & $6.05[4.98 ; 7.13]$ \\
\hline$>68$ Letters & 464 & $5.64[5.30 ; 5.99]$ & 309 & $4.64[5.25 ; 6.04]$ & 72 & $6.38[5.26 ; 7.49]$ \\
\hline \multicolumn{7}{|c|}{ Participants receiving a four-injection upload ${ }^{\mathrm{c}}$} \\
\hline Total & & $1226(100.0 \%)$ & & $774(100.00 \%)$ & & $181(100.0 \%)$ \\
\hline Yes & & $410(33.4 \%)$ & & $270(34.9 \%)$ & & $46(25.4 \%)$ \\
\hline No & & $816(66.6 \%)$ & & $504(65.1 \%)$ & & $135(74.6 \%)$ \\
\hline \multicolumn{7}{|c|}{ Number of OCT examinations } \\
\hline To month 12 & 1226 & $3.7[3.5 ; 3.9]$ & 774 & $3.7[3.5 ; 3.9]$ & 181 & $4.0[3.6 ; 4.4]$ \\
\hline To month 24 & 1226 & $5.9[5.6 ; 6.2]$ & 774 & $5.9[5.5 ; 6.4]$ & 181 & $6.5[5.7 ; 7.3]$ \\
\hline
\end{tabular}

Only participants completing the 24 months observational period

Number of injections in the first year (to month 12), by baseline VA ${ }^{\mathrm{b}}$ in ETDRS letters

$\begin{array}{lllllll}<55 \text { Letters } & 210 & 4.92[4.61 ; 5.23] & 120 & 5.05[4.63 ; 5.47] & 36 & 5.22[4.36 ; 6.09] \\ 55-68 \text { Letters } & 239 & 4.62[4.35 ; 4.89] & 148 & 4.77[4.43 ; 5.11] & 34 & 4.68[3.87 ; 5.48] \\ >68 \text { Letters } & 288 & 4.80[4.52 ; 5.07] & 186 & 4.88[4.54 ; 5.21] & 45 & 5.29[4.51 ; 6.06]\end{array}$

Number of injections over the observational period (to month 24), by baseline VA ${ }^{\mathrm{b}}$ in ETDRS letters

$\begin{array}{lllllll}<55 \text { Letters } & 210 & 6.61[6.06 ; 7.16] & 120 & 6.72[5.99 ; 7.45] & 36 & 7.31[5.75 ; 8.87] \\ 55-68 \text { Letters } & 239 & 6.16[5.68 ; 6.65] & 148 & 6.15[5.55 ; 6.74] & 34 & 7.32[5.86 ; 8.79] \\ >68 \text { Letters } & 288 & 6.48[6.00 ; 6.96] & 186 & 6.50[5.95 ; 7.05] & 45 & 7.64[6.07 ; 9.21]\end{array}$

Participants receiving a four-injection upload ${ }^{\mathrm{c}}$

\begin{tabular}{|c|c|c|c|c|c|c|}
\hline Total & & $738(100.0 \%)$ & & $455(100.0 \%)$ & & $115(100.0 \%)$ \\
\hline Yes & & $241(32.7 \%)$ & & $155(34.1 \%)$ & & $31(27.0 \%)$ \\
\hline No & & $497(67.3 \%)$ & & $300(65.9 \%)$ & & $84(73.0 \%)$ \\
\hline \multicolumn{7}{|c|}{ Jumber of OCT examinations } \\
\hline To month 12 & 738 & $4.1[3.8 ; 4.3]$ & 445 & $4.2[3.8 ; 4.5]$ & 115 & $4.6[4.0 ; 5.2]$ \\
\hline To month 24 & 738 & $7.5[7.0 ; 7.9]$ & 445 & $7.6[6.9 ; 8.2]$ & 115 & $8.4[7.3 ; 9.4]$ \\
\hline
\end{tabular}

CI confidence interval, ETDRS Early Treatment Diabetic Retinopathy Study, $V A$ visual acuity

${ }^{a}$ Values are presented as the mean with the $95 \%$ confidence interval (CI) in square brackets or as a number with the percentage in parenthesis, as appropriate

b VA was assessed as best-corrected VA

${ }^{c}$ Counted are patients with three injections after the baseline injection, with not more than 37 days between each injection in this series and the previous one 


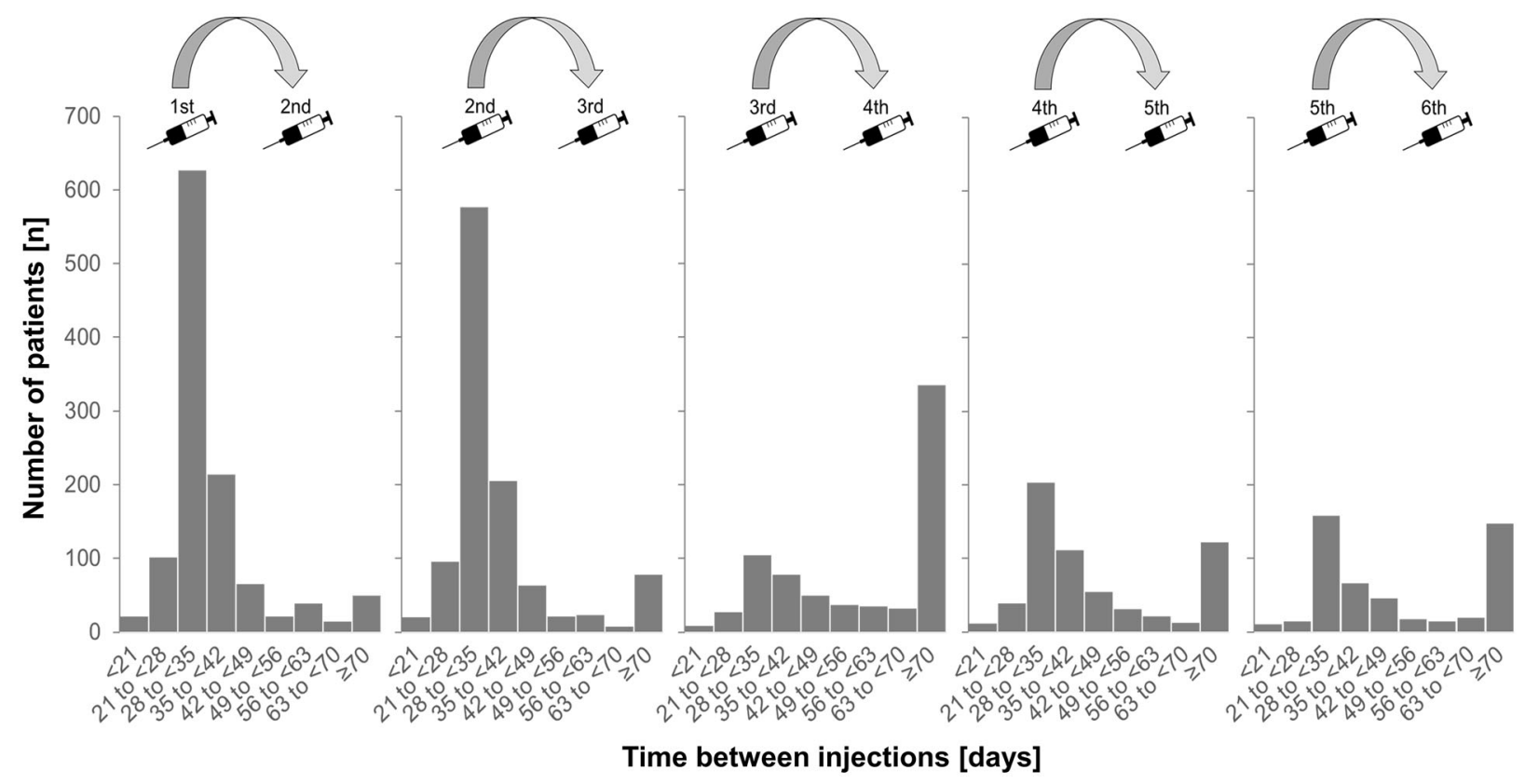

Fig. 3 Time intervals between the first five injections during the OCEAN study and the respective next injection. Number of patients are plotted against the respective category of time intervals (days)

those receiving $\geq 7$ injections. The number of injections was similar in the subgroups according to baseline VA (Table 2). Overall, VA improvements were comparable between pretreated and treatment-naïve participants in the first year, but slightly better in the pre-treated group towards the end of the study (Fig. 4a). At 24 months, $32.7 \%$ of the pre-treated but only $20.3 \%$ of the treatment-naïve participants had gained $\geq 15$ ETDRS letters.

\section{Time-to-Event Analyses}

The rate of premature study discontinuation was relatively constant throughout the study (Fig. 5a). The probability of a participant remaining in the study up to month 12 and month 24 was approximately 75 and 60\%, respectively. The rate and time course of discontinuations did not differ by pre-treatment status (Fig. 5b), sex and baseline VA (ESM Fig. S3a, b). A higher proportion of participants receiving one to three injections during the first 12 months were documented for a shorter period of time compared to those receiving more injections (ESM Fig. S3c).
Time-to-response and duration-of-response were analyzed by pre-treatment status and number of documented ranibizumab injections in the first year.

About 20\% of treatment-naïve participants had $\mathrm{a} \geq 15$ ETDRS letter response within the first 3 months in all injection subgroups. Thereafter, the response rate was higher in participants receiving $\geq 7$ injections than in those receiving fewer injections (Fig. 6a). In participants who showed $\mathrm{a} \geq 15$ ETDRS letter response, the duration-of-response was lowest in those with the most injections and highest in those with the least injections. The probability of $\mathrm{a} \geq 15$ ETDRS letter response lasting $\geq 3$ months was 58 and $37 \%$ in the subgroups receiving one to three and $\geq 7$ injections, respectively (Fig. 7a). Timeto-response and duration-of-response did not vary by sex. More participants with low baseline VA ( $<55$ ETDRS letters) responded, and their response was faster and lasted longer than that in the subgroups with higher VA (ESM Figs. S5a, b, S6a, b).

The results were similar for the pre-treated population (Figs. 6b, 7b; ESM Figs. S4c, d, S5c, d) but less reliable due to the small group size. 
Table 3 Visual acuity of participants with diabetic macular edema in the OCEAN study, at baseline and at months 12 and 24 of the observational period (full analysis set, $n=1226$ )

\begin{tabular}{|c|c|c|c|c|c|c|}
\hline \multirow[t]{2}{*}{ Parameter } & \multicolumn{2}{|c|}{ All participants } & \multicolumn{2}{|c|}{ Treatment-naïve } & \multicolumn{2}{|c|}{ Pre-treated } \\
\hline & $n$ & Values $^{a}$ & $n$ & Values $^{a}$ & $n$ & Values $^{a}$ \\
\hline \multicolumn{7}{|l|}{ Visual acuity ${ }^{\mathrm{b}}$, ETDRS letters } \\
\hline Baseline & 1217 & $60.6[59.7 ; 61.5]$ & 767 & $61.5[60.4 ; 62.5]$ & 180 & $61.2[59.0 ; 63.3]$ \\
\hline Month 12 & 642 & $65.0[63.5 ; 66.5]$ & 418 & $65.6[63.8 ; 67.5]$ & 87 & $64.8[60.7 ; 68.8]$ \\
\hline Month 24 & 371 & $65.5[63.5 ; 67.4]$ & 238 & $66.4[64.1 ; 68.6]$ & 49 & $67.0[61.9 ; 72.2]$ \\
\hline$\Delta$ Mo $12-B L$ & 638 & $+4.0[2.9 ; 5.2]$ & 414 & $+4.1[2.7 ; 5.6]$ & 87 & $+3.6[0.0 ; 7.1]$ \\
\hline$\Delta$ Mo $24-B L$ & 370 & $+5.2[3.7 ; 6.7]$ & 237 & $+5.4[3.7 ; 7.0]$ & 49 & $+6.3[2.8 ; 9.9]$ \\
\hline \multicolumn{7}{|c|}{ Participants with documented response at month 24 in ETDRS letters } \\
\hline Total & & $638(100.0 \%)$ & & $414(100.0 \%)$ & & $87(100.0 \%)$ \\
\hline$\geq 15$ Letter gain & & $137(21.5 \%)$ & & $89(21.5 \%)$ & & $18(20.7 \%)$ \\
\hline Change between $\geq 15$ and $<15$ letters & & $455(71.3 \%)$ & & $297(71.7 \%)$ & & $61(70.1 \%)$ \\
\hline$\geq 15$ letter loss & & $46(7.2 \%)$ & & $28(6.8 \%)$ & & $8(9.2 \%)$ \\
\hline \multicolumn{7}{|c|}{ Participants with documented response at month 24 in ETDRS letters } \\
\hline Total & & $370(100.0 \%)$ & & $237(100.0 \%)$ & & $49(100.0 \%)$ \\
\hline$\geq 15$ Letter gain & & $87(23.5 \%)$ & & $48(20.3 \%)$ & & $16(32.7 \%)$ \\
\hline Change between $\geq 15$ and $<15$ letters & & $257(69.5 \%)$ & & $176(74.3 \%)$ & & $29(59.2 \%)$ \\
\hline$\geq 15$ Letter loss & & $26(7.0 \%)$ & & $13(5.5 \%)$ & & $4(8.16 \%)$ \\
\hline
\end{tabular}

BL Baseline, Mo month

${ }^{a}$ Values are presented as the mean with the $95 \% \mathrm{CI}$ in square brackets or as a number with the percentage in parenthesis, as appropriate

${ }^{\mathrm{b}}$ Visual acuity was assessed as best-corrected VA

\section{Safety}

One or more AEs (non-serious and/or serious) were reported for 256 of the 1250 participants in the safety population (20.5\%). The most common ocular AEs were increased intraocular pressure $(2.6 \%)$, reduced VA $(2.4 \%)$, vitreous hemorrhage, cataract operation (1.4\% each) and posterior capsule opacification (1.0\%) (ESM
Table S3). Serious AEs (SAEs) were reported in 143 participants $(11.4 \%)$. The most frequent ocular SAEs were vitreous hemorrhage and reduced VA (1.0\% each). One SAE of endophthalmitis was reported $(0.1 \%)$. The main nonocular SAEs were death (1.0\%) and cerebrovascular accident $(0.7 \%)$. 
(a)

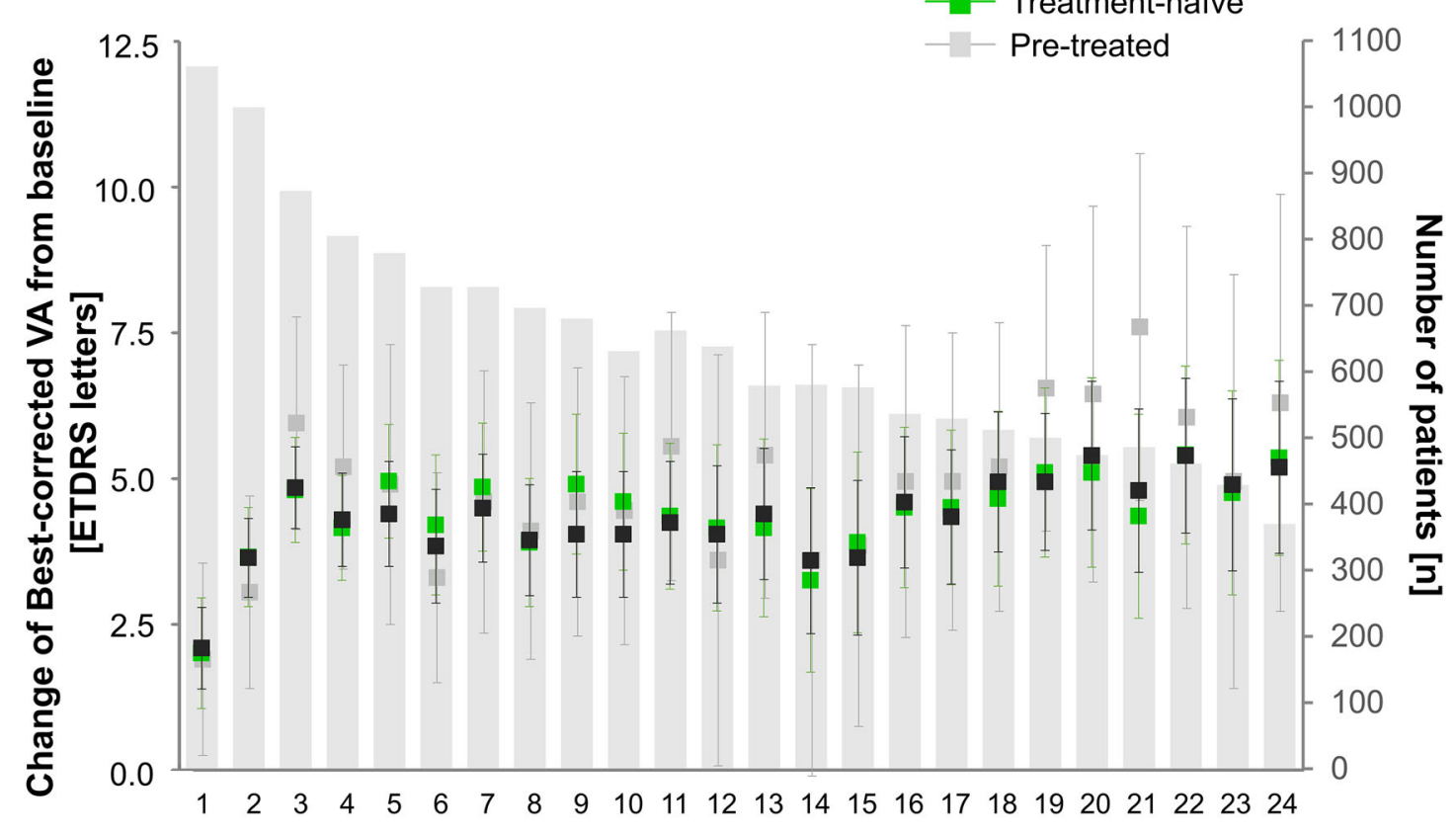

Month / Visit

(b)

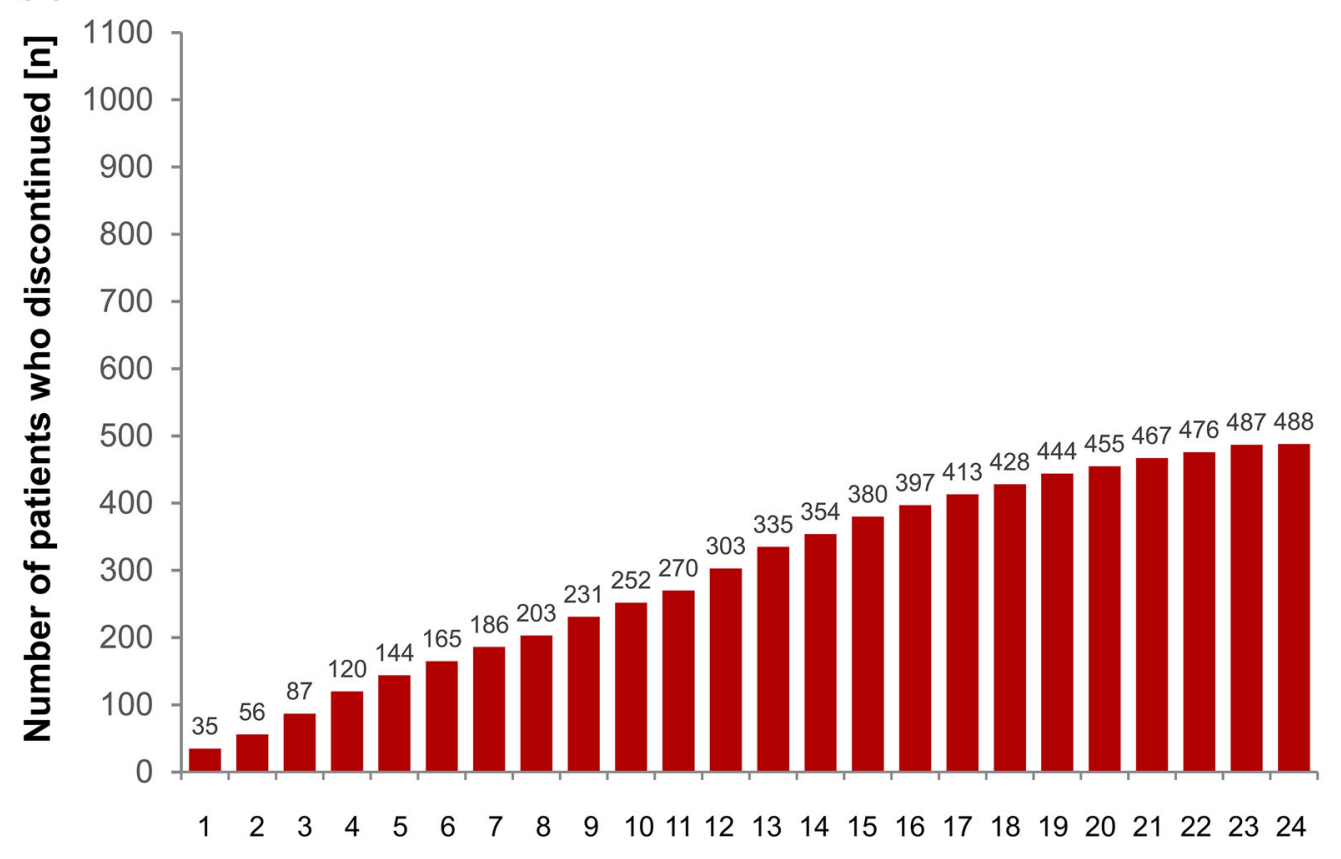

\section{Month / Visit}

Fig. 4 Mean change of best-corrected visual acuity $(V A)$ from baseline in participants with DME by pre-treatment status (a), and the corresponding total number of patients who discontinued the study (b) during the 24-month observational period. ETDRS Early Treatment Diabetic Retinopathy Study, Boxes in a represent mean changes and error bars represent $95 \%$ confidence intervals (CI). Gray bars represent number of patients 

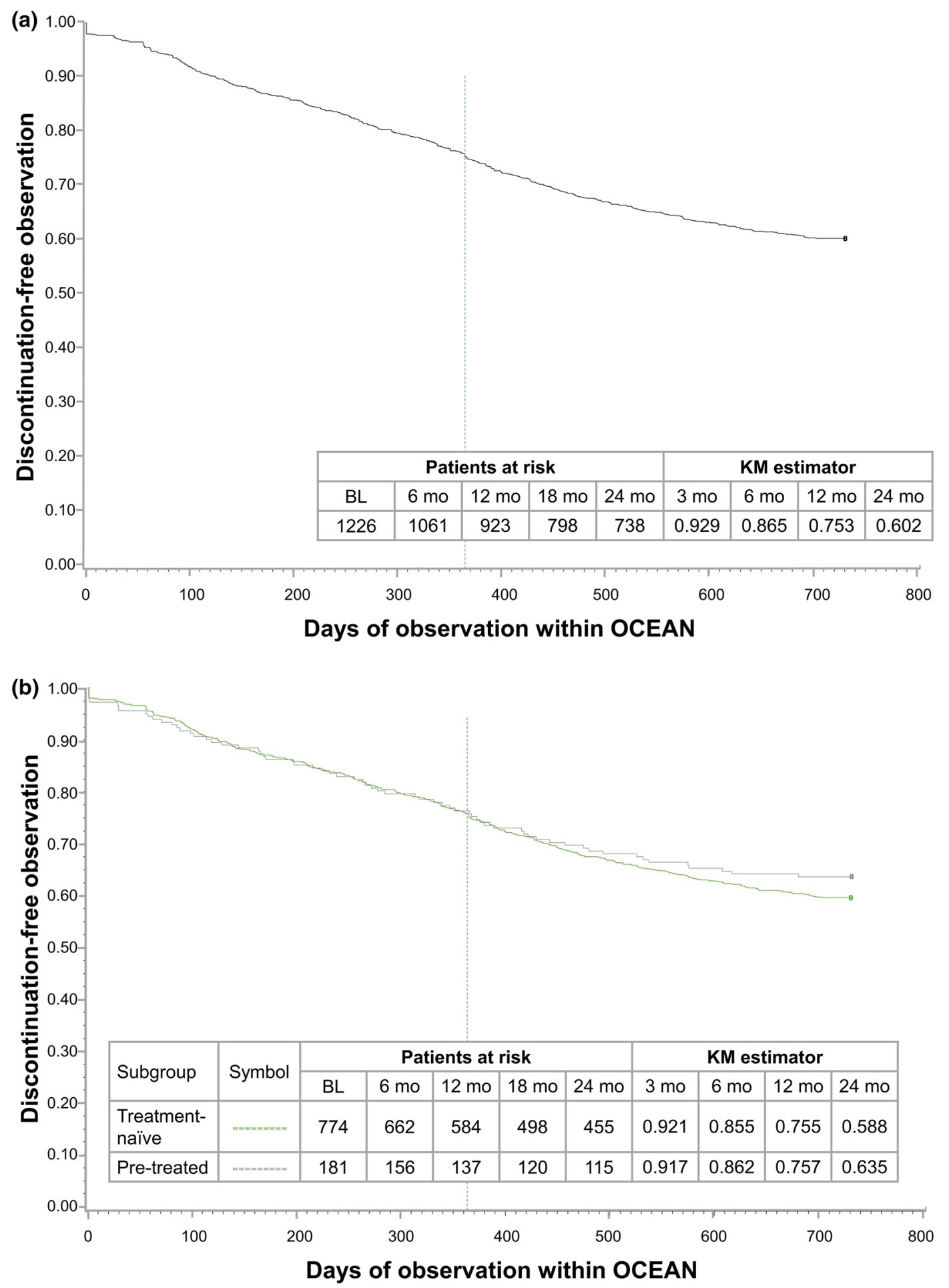

Fig. 5 Time-to-discontinuation in all patients (full analysis set $[\mathrm{FAS}] n=1226$ ) (a) and by pre-treatment status (b). If the time of discontinuation was not documented, it was set to day 1. Estimators are based on the
Kaplan-Meier $(K M)$ product-limit methodology. $B L$ Baseline, mo Months. The dashed line represents the 1 year time point 

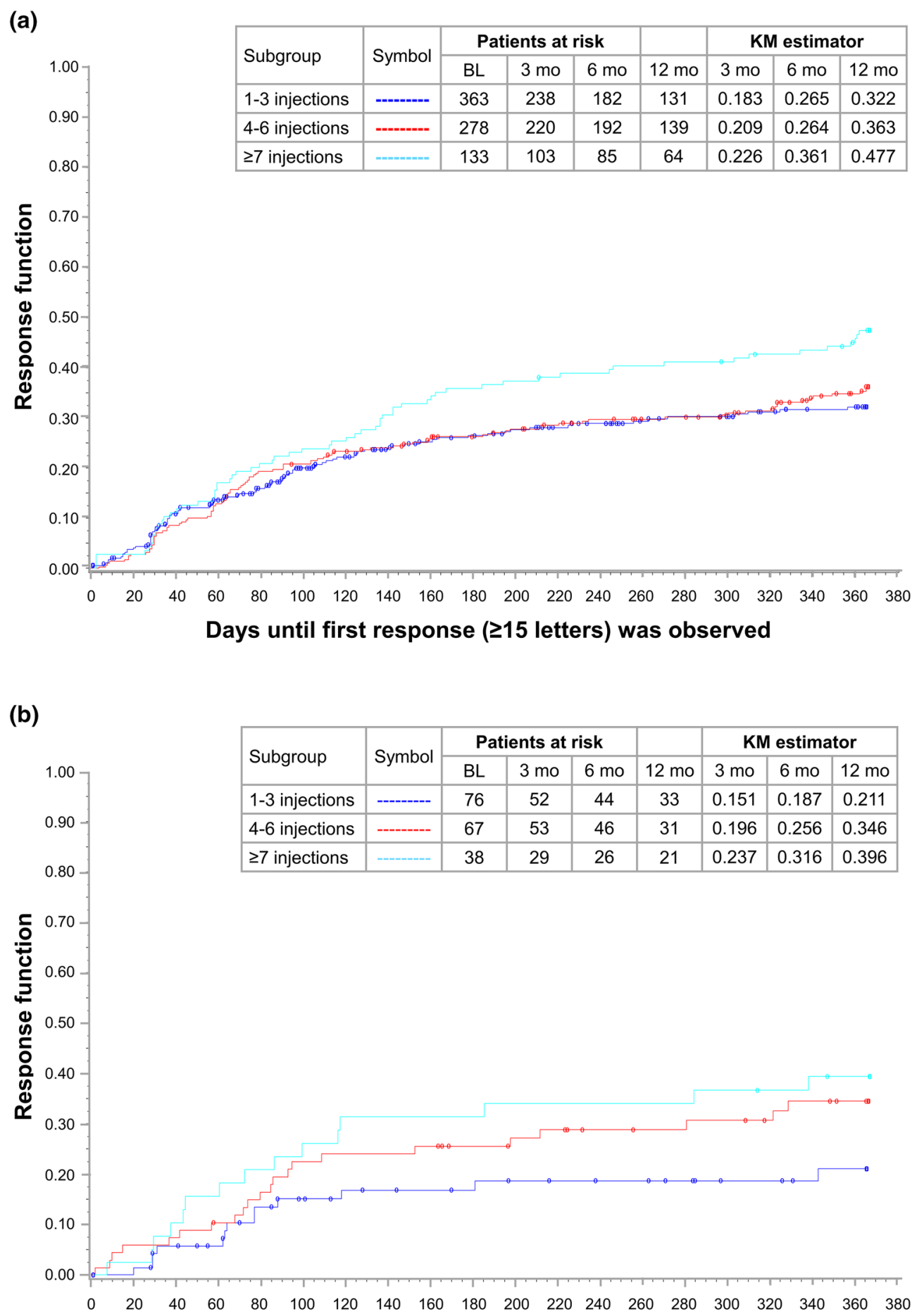

Days until first response ( $\geq 15$ letters) was observed

Fig. 6 Time-to-response (VA improvement of $\geq 15$ ETDRS letters from baseline) in treatment-naïve (a) and pre-treated participants (b). Time-to-response was defined as the first time an improvement of $\geq 15$ letters from baseline was reached. Participants who did not reach a response were censored at the last documented time point. If no visual acuity data were documented after baseline, the participant was censored on day 1. Estimators are based on the Kaplan-Meier product-limit methodology. See Fig. 5 caption for abbreviations 
(a)

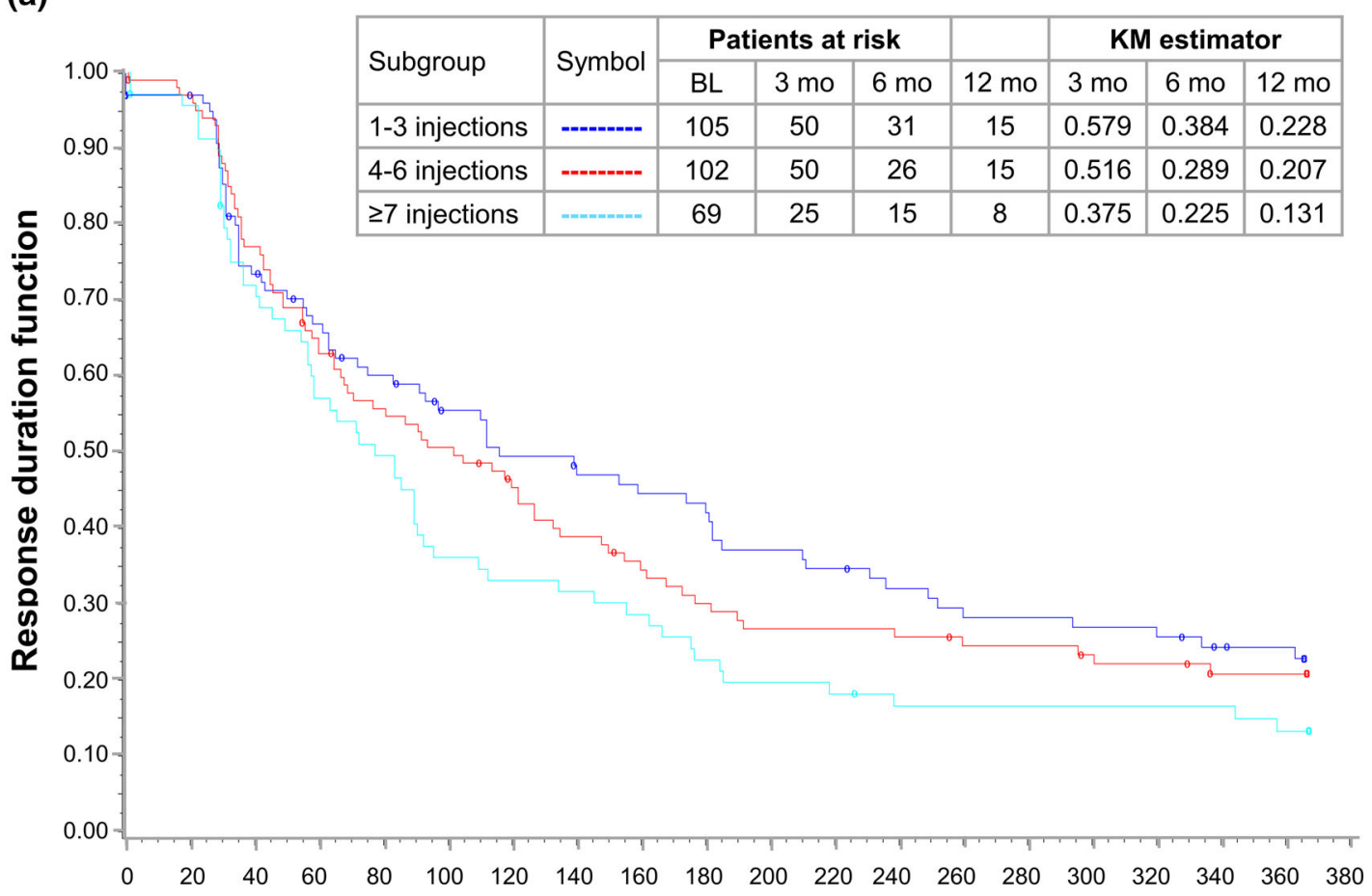

Duration of response in days after first response ( $\geq 15$ letters) was observed

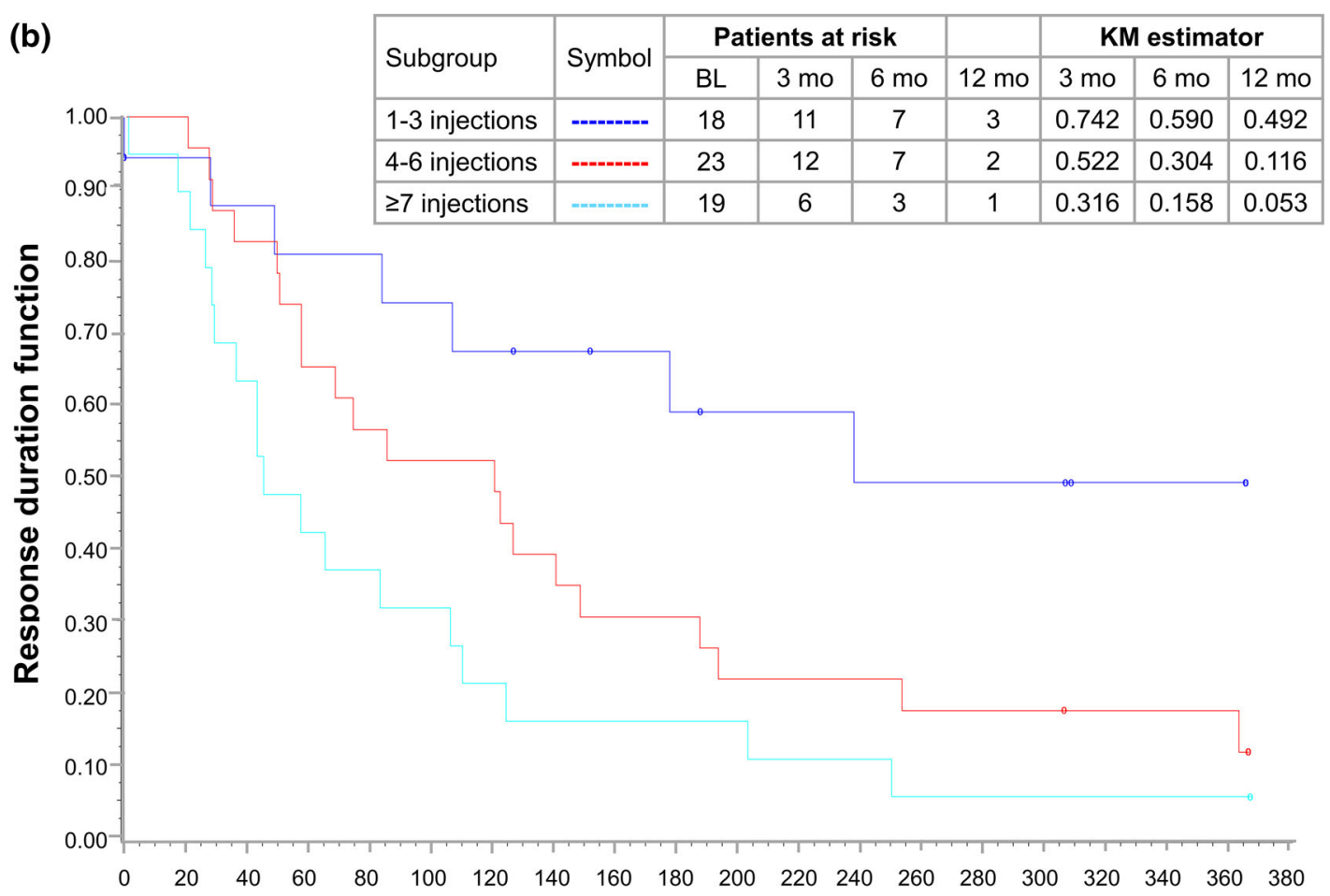

Duration of response in days after first response ( $\geq 15$ letters) was observed 
4Fig. 7 Duration-of-response (time from first improvement of $\geq 15$ ETDRS letters to first time point of losing this improvement) in treatment-naive (a) and pre-treated participants (b). Duration-of-response was defined as the time from first improvement of $\geq 15$ letters from baseline to the first time point of losing this improvement. Participants who did not lose the response were censored at the last documented time point where the response was still present. If no visual acuity data were documented after the response date, the participant was censored on day 1. Estimators are based on the Kaplan-Meier product-limit methodology. See Fig. 5 caption for abbreviations

\section{DISCUSSION}

The real-world treatment of visual impairment due to DME with intravitreal ranibizumab suggests insufficient monitoring and potential under-treatment in Germany. Similar problems have been described in neovascular age-related macular degeneration (nAMD) $[19,20]$, but only retrospective data are available on DME [13, 14, 21-24]. Even though the mean number of injections and OCT examinations in our study did not meet current German recommendations, VA gains of $\geq 15$ ETDRS letters were reported for over $20 \%$ of the participants. Improvements occurred largely within 3 months and were sustained up to month 24 . The participants receiving the most $(\geq 7)$ injections in the first year responded the fastest, but their response was less sustained than that of participants receiving fewer injections.

With a mean of 4.42 and 5.52 ranibizumab injections administered over 12 and 24 months, respectively, OCEAN participants with DME received notably fewer than the 7-12 and three to six injections administered in the first and second year, respectively, in previous clinical trials $[2,3,9,10]$. A complete four-injection upload as recommended for DME [8] was documented only in one-third of the participants. These low re-injection rates observed in the study were obtained under conditions of a phase 4 study; as such, they may indicate an even worse re-treatment rate in the "unobserved" routine real-life setting.

Under-treatment with anti-VEGF injections was also observed in retrospective chart reviews of DME. A median of six injections in year 1 and one to two injections in year 2 were documented for 333 individuals with DME at a single German center [14]. Similarly, a recently published German chart review study with 235 patients documented an average of 5.7 injections in the first year of DME treatment [24]. This is below the recommendations but still slightly higher than the number of injections in OCEAN, potentially due to a selection bias, as only individuals with $\geq 1$ year of follow-up and still actively followed in the clinic were included. OCEAN participants with DME were recruited from 250 centers, including 49 general ophthalmology practices, where monitoring and treatment were documented, but patients were referred to a retina specialist for the injections. Such referrals have been shown to delay treatment start [16] and may also affect further treatment $[25,26]$.

Based on retrospective data from the U.S. IRIS ${ }^{\circledR}$ Registry, a comprehensive eye disease and condition registry, only $47 \%$ of people with DME were treated within 1 year of diagnosis. Those given anti-VEGF in the first year received on average 4.2 injections, similar to the number of injections received by participants in OCEAN [27]. In another USA-based retrospective multicenter study, 156 individuals with DME received on average 5.8 injections in year 1 and 5.0 injections in year 2 [13], while a third retrospective real-world study in the USA found that patients only received 3.1 injections in the first year of DME treatment [28]. A Danish retrospective cohort study including 566 patients found that on average 6.1 intravitreal antiVEGF injections were received in year 1 and 3.0 in year 2 [29]. Discrepancies between these studies and OCEAN in terms of the number of injections may be due to selection bias or different clinical practice and reimbursement in the USA.

The low number of ranibizumab injections in OCEAN may be due to insufficient OCT monitoring, which is not routinely provided in Germany [20]. On average, only 3.7 and 5.9 OCT examinations were reported over 12 and 24 months. Very similar figures for Germany were described in another European study (POLARIS), which supports the meaningfulness 
of the OCEAN data [30]: the rare use of OCT was also evident in the POLARIS study from the high number of VA examinations. One possible reason for the lower use of OCT may be that OCT examinations in Germany are not reimbursed by the national health insurance and is therefore only included in individual selective contracts or offered as a self-payer service. Some of the OCEAN centers did not even have an OCT device at the start of the study despite the importance of the morphological re-treatment criteria. Many German ophthalmologists refrained from OCT controls during the followup. Another finding reported by the authors of the POLARIS study enables comparison between European countries: in Germany treatment often stops or is delayed after the first three injections; in comparison, the higher rate of OCT examinations in the UK was also associated with a considerably higher number of ranibizumab injections [30].

Non-adherence to monitoring and treatment is a known problem in DME [28]. In a German real-world study that included 136 individuals with DME receiving anti-VEGF only 35\% adhered to the visit schedule [12]. Another realworld study in Germany that included 134 individuals with DME receiving anti-VEGF found a non-adherence rate of $44 \%$, which was mostly patient associated [23]. Possible reasons for non-adherence include comorbidities, patient age $[12,23]$ and/or the high visit burden, particularly since individuals with DME also require frequent diabetes monitoring. It has also been suggested that adherence may be hampered by reimbursement issues, mobility limitations, a lack of patient motivation and interference with work schedules [28]. Even with appropriate monitoring, some physicians may use re-injection criteria that differ from the recommendations. It is also possible that recommendations were followed but that participants were not treated because they met success or stop criteria or refused treatment; while this last possibility cannot be discerned from the data, but it is unlikely.

Despite under-treatment, VA notably improved in OCEAN participants with DME after 12 months (+ 4.0 ETDRS letters) and 24 months $(+5.2$ letters). Participants with low baseline VA ( $<55$ letters) and those receiving $\geq 7$ injections in year 1 showed the highest gains. The VA improved less than in patients with DME in randomized controlled trials such as. RESTORE [7], Protocol I [31] and Protocol T [2] where participants given ranibizumab with or without laser photocoagulation gained between +7 and +12 ETDRS letters. Clinical trials have strict treatment and follow-up schedules and inclusion/exclusion criteria, which may lead to better outcomes.

The VA improvements in patients in the prospective OCEAN study were also slightly lower than improvements reported in retrospective chart reviews. Two UK-based studies showed improvements of +5 ETDRS letters [22] and +6.6 letters [21] at 12 months. The latter study selected individuals receiving $a \geq 3$-injection upload who may be expected to have better results. In a German retrospective study [14], the maximum improvement for DME within 12 months was +6.2 ETDRS letters, but the change from baseline to month 12 was - 1.3 letters. This VA loss may be due to bias, as only patients still under treatment were included, preferentially selecting individuals with chronically active disease [14]. A second German chart review study documented VA gains of +5.6 ETDRS letters in the first year of ranibizumab treatment [24]. A small retrospective study from Taiwan found average improvement of +4.9 ETDRS letters at 12 months with a mean injection load of 4.3 injections [32].

About $60 \%$ of the participants completed the OCEAN study, which is comparable with other non-interventional studies, such as the AURA study on ranibizumab treatment for nAMD, where 53\% completed 2 years [33]. Time-toevent analyses have the advantage of including participants irrespective of the length of their individual observational period and missing data. The discontinuation rate among the participants in the OCEAN study was quite constant, suggesting that no specific factor triggered discontinuation at a particular time point. Participants receiving one to three injections during year 1 were documented for a shorter period than participants with more injections. It cannot be determined whether 
participants leaving the study early continued treatment outside the study.

Over $20 \%$ of the OCEAN participants with DME showed a relevant VA improvement ( $\geq 15$ ETDRS letters) at months 12 and 24. Most participants responded within 3 months, consistent with the fast responses shown in clinical trials $[2,7]$. The response rate was higher in individuals receiving $\geq 7$ injections in year 1 , suggesting that more injections, potentially due to better adherence, increase VA gains. However, as a considerable proportion of participants discontinued the study early, and the group with $\geq 7$ injections was small, this finding may not be transferrable to the general DME population.

By contrast, the duration-of-response was shortest in participants receiving the most injections. This could mean that participants receiving more injections do so because they respond to treatment but require additional ranibizumab injections to maintain the beneficial effects, such as due to higher disease activity.

Participants with the lowest baseline VA $(<55$ ETDRS letters) showed the highest VA gain ('floor effect'), and the response was faster and lasted longer than that in the subgroups with higher VA, demonstrating that individuals with DME and significantly impaired VA achieve sustainable improvements with ranibizumab. Participants with baseline VA of $>68$ ETDRS letters gained less ('ceiling effect') but maintained higher VA than that of the other subgroups, supporting the need for prompt monitoring and treatment to prevent vision loss from DME [34].

No new safety findings were identified in this population. The documented incidence of AEs $(20.5 \%)$ and SAEs (11.4\%) over 2 years was lower than those reported in randomized trials $[2,31]$, potentially due to under-reporting in this non-interventional setting.

The non-interventional design is a strength of this study, as it describes the use of ranibizumab therapy for DME in routine clinical practice, in patients who are older and have more comorbidities than those in clinical trials $[11,15]$ and who may also have more difficulties adhering to the treatment schedule. Seeing a beneficial effect of ranibizumab with a wellcharacterized safety profile in this setting is encouraging.

Non-interventional studies harbor a number of important limitations, including non-standardized diagnostics, high discontinuation rates, under-reporting, artificial patient selection and selective reporting; all of these have to be kept in mind when interpreting the results. Although even randomized controlled trials reported a loss of follow-up of between $23.4 \%$ (NCT00473382) and 42.1\% (NCT00168389) of DME patients over 3 years, the group of discontinued documentation and treatment in the daily routine is more strongly associated with a distortion potential and thus does likely not reflect the actual distribution of the functional response. In this study, we have tried to describe this window of uncertainty and take account the limited tracking through a transparent and robust methodology.

\section{CONCLUSION}

In conclusion, the large non-interventional OCEAN study demonstrated that despite insufficient monitoring and potential under-treatment, substantial improvements of VA could be achieved with ranibizumab $(0.5 \mathrm{mg})$ in $>20 \%$ of adults with DME. As the response rate was higher in participants receiving more injections, improving access and adherence to treatment may increase the benefits of this costand resource-intensive therapy.

\section{ACKNOWLEDGEMENTS}

We would like to thank all study participants for their time and good cooperation. The authors would also like to thank the collaborators for the ORCA study group, Teresa Barth (University Eye Hospital, Regensburg) and Chris P. Lohmann (Klinikum Rechts der Isar, Munich).

The Participants of the OCEAN Group are listed in the Supplementary Materials. 
Funding. Novartis Pharma GmbH, Nuremberg, Germany, developed and funded the study, and the associated article processing charges. All authors had full access to all of the data in this study and take complete responsibility for the integrity of the data and accuracy of the data analysis.

Assistance. Assistance in project management, statistical analysis and medical writing was provided by Klaus Laschke (statistics), Bianca Arendt and Annemarie Hütz (medical writing) and Susanne Faber (project management), all Kantar Health GmbH, Munich, Germany, and Caroline Dunstall (medical writing). Support for this assistance was funded by Novartis Pharma GmbH, Germany.

Authorship. All named authors meet the International Committee of Medical Journal Editors (ICMJE) criteria for authorship for this article, take responsibility for the integrity of the work as a whole, and have given their approval for this version to be published.

Disclosures. Focke Ziemssen received grants and personal fees from Biogen, Allergan, Alimera, Bayer Healthcare and Roche; grants from Clearside; and personal fees from Boehringer Ingelheim, Novartis, MSD Sharp \& Dohme. Joachim Wachtlin received fees from Novartis, Bayer, Alcon, Allergan and was an advisory board member for Novartis, Bayer and Alcon. Laura Kuehlewein received research support from the Tistou and Charlotte Kerstan Foundation, Retina Implant AG and Novartis. MariaAndreea Gamulescu received speaker's fees from Novartis. Thomas Bertelmann received research grants from Novartis and personal fees from Alcon, Alimera, Allergan, Bayer (Heidelberg) and Novartis, and was a Medical Advisor for Novartis (2015-2016). Nikolaus Feucht received speaker's fees from Heidelberg Engineering, Novartis and Bayer, and was member of an advisory board for Allergan. Jessica Voegeler is a Novartis employee. Mirja Koch is a Novartis employee. Sandra Liakopoulos received speaker's fees from Novartis, Carl Zeiss Meditec, Allergan, Bayer, and was member of an advisory board for Novartis. Steffen Schmitz-Valckenberg received grants and non-financial research funding from Accucela, Alcon/Novartis, Allergan, Bayer, Bioeq/Formycon, Centervue, Genentech/Roche, Heidelberg Engineering, Optos, Carl Zeiss MediTec, and personal fees and honoraria from Alcon/Novartis, Bayer, Genentech/Roche and Carl Zeiss MediTec. Georg Spital received personal fees from Bayer Healthcare, Novartis, Zeiss and OD-OS.

Compliance with Ethics Guidelines. The OCEAN study was approved by the ethics committee of the Eberhard-Karls-University, Tuebingen, Germany. All procedures performed in studies involving human participants were in accordance with the ethical standards of the institutional and/or national research committee and with the 1964 Helsinki declaration and its later amendments or comparable ethical standards. Informed consent was obtained from all individual participants included in the study.

Data Availability. The datasets generated during and/or analyzed during the current study are not publicly available due to German data protection law but are available from the corresponding author on reasonable request.

Open Access. This article is distributed under the terms of the Creative Commons Attribution-NonCommercial 4.0 International License (http://creativecommons.org/licenses/ by-nc/4.0/), which permits any noncommercial use, distribution, and reproduction in any medium, provided you give appropriate credit to the original author(s) and the source, provide a link to the Creative Commons license, and indicate if changes were made.

\section{REFERENCES}

1. Tan GS, Cheung N, Simo R, Cheung GC, Wong TY. Diabetic macular oedema. Lancet Diabetes Endocrinol. 2017;5(2):143-55.

2. Wells JA, Glassman AR, Ayala AR, et al. Aflibercept, bevacizumab, or ranibizumab for diabetic macular edema: two-year results from a comparative 
effectiveness randomized clinical trial. Ophthalmology. 2016;123(6):1351-9.

3. Elman MJ, Ayala A, Bressler NM, et al. Intravitreal ranibizumab for diabetic macular edema with prompt versus deferred laser treatment: 5-year randomized trial results. Ophthalmology. 2015;122(2):375-81.

4. Virgili G, Parravano M, Evans JR, Gordon I, Lucenteforte E. Anti-vascular endothelial growth factor for diabetic macular oedema: a network meta-analysis. Cochrane Database Syst Rev. 2017;6:CD007419. https://doi.org/10.1002/14651858.CD007419.pub5.

5. Avitabile T, Azzolini C, Bandello F, et al. Aflibercept in the treatment of diabetic macular edema: a review and consensus paper. Eur J Ophthalmol. 2017;27(6):627-39.

6. Bahrami B, Hong T, Gilles MC, Chang A. Anti-VEGF therapy for diabetic eye diseases. Asia-Pac J Ophthalmol. 2017;6(6):535-45.

7. Schmidt-Erfurth U, Lang GE, Holz FG, et al. Threeyear outcomes of individualized ranibizumab treatment in patients with diabetic macular edema: the RESTORE extension study. Ophthalmology. 2014;121(5):1045-53.

8. Deutschen Ophthalmologischen Gesellschaft (DOG), Retinologischen Gesellschaft (RG), Berufsverbandes der Augenärzte Deutschlands (BVA). Therapie der diabetischen makulopathie. Ophthalmologe. 2013;110:568-88.

9. Dugel PU, Hillenkamp J, Sivaprasad S, et al. Baseline visual acuity strongly predicts visual acuity gain in patients with diabetic macular edema following anti-vascular endothelial growth factor treatment across trials. Clin Ophthalmol. 2016;10:1103-10.

10. Payne JF, Wykoff CC, Clark WL, et al. Randomized trial of treat and extend ranibizumab with and without navigated laser for diabetic macular edema: TREX-DME 1 year outcomes. Ophthalmology. 2017;124(1):74-81.

11. Ziemssen F, Feltgen N, Holz FG, et al. Demographics of patients receiving intravitreal anti-VEGF treatment in real-world practice: healthcare research data versus randomized controlled trials. BMC Ophthalmol. 2017;17(1):7.

12. Weiss M, Sim DA, Herold T, et al. Compliance and adherence of patients with diabetic macular edema to intravitreal anti-vascular endothelial growth factor therapy in daily practice. Retina. 2017. doi: https://doi.org/10.1097/IAE.0000000000001892.

13. Blinder KJ, Dugel PU, Chen S, et al. Anti-VEGF treatment of diabetic macular edema in clinical practice: effectiveness and patterns of use (ECHO Study Report 1). Clin Ophthalmol. 2017;11:393-401.

14. Wecker T, Ehlken C, Buhler A, et al. Five-year visual acuity outcomes and injection patterns in patients with pro-re-nata treatments for AMD, DME, RVO and myopic CNV. Br J Ophthalmol. 2017;101(3):353-9.

15. Ziemssen F, Stahl A, Dimopoulos S. Versorgungsforschung der anti-VEGF-therapie: selektion und methodische besonderheiten. Klin Monatsbl Augenheilkd. 2017;234(12):1483-92.

16. Ziemssen F, Bertelmann T, Hufenbach U, et al. Delayed treatment initiation of more than 2 weeks. Relevance for possible gain of visual acuity after anti-VEGF therapy under real life conditions (interim analysis of the prospective OCEAN study). Ophthalmologe. 2016;113(2):143-51.

17. World Health Organization. Safety of medicines-a guide to detecting and reporting adverse drug reactions-why health professionals need to take action. Geneva: World Health Organization; 2002. http://apps.who.int/medicinedocs/en/d/Jh2992e/. Accessed 30 Nov 2017.

18. The Association of the British Pharmaceutical Industry. Guidance-demonstrating value with real world data: a practical guide. London: The Association of the British Pharmaceutical Industry; 2011. http://www.abpi.org.uk/our-work/library/guidelines/ Pages/real-world-data.aspx. Accessed 30 Nov 2017.

19. Ziemssen F, Eter N, Fauser S, et al. Retrospective investigation of anti-VEGF treatment reality and effectiveness in patients with neovascular age-related macular degeneration (AMD) in Germany: treatment reality of ranibizumab for neovascular AMD in Germany. Ophthalmologe. 2015;112(3):246-54.

20. Finger RP, Wiedemann P, Blumhagen F, Pohl K, Holz FG. Treatment patterns, visual acuity and quality-of-life outcomes of the WAVE study-a noninterventional study of ranibizumab treatment for neovascular age-related macular degeneration in Germany. Acta Ophthalmol. 2013;91(6):540-6.

21. Patrao NV, Antao S, Egan C, et al. Real-world outcomes of ranibizumab treatment for diabetic macular edema in a United Kingdom National Health Service setting. Am J Ophthalmol. 2016;172:51-7.

22. Egan C, Zhu H, Lee A, et al. The United Kingdom Diabetic Retinopathy Electronic Medical Record Users Group, Report 1: baseline characteristics and visual acuity outcomes in eyes treated with intravitreal injections of ranibizumab for diabetic macular oedema. Br J Ophthalmol. 2017;101(1):75-80. 
23. Ehlken C, Helms M, Boehringer D, Agostini HT, Stahl A. Association of treatment adherence with real-life VA outcomes in AMD, DME, and BRVO patients. Clin Ophthalmol. 2018;12:13.

24. Wilke RG, Finger RP, Sachs HG. Real-life data on the treatment of diabetic macular oedema in Germany. Klin Monatsbl Augenheilkd. 2017;234(12):1502-7.

25. Botha VE, Ah-Chan JJ, Ramachandran N. Improving accessibility to intravitreal anti-vascular endothelial growth factor treatment for ophthalmic patients in a peripheral centre. $\mathrm{N} Z$ Med J. 2016;129(1445):56-66.

26. Gillies MC, Walton R, Simpson JM, et al. Prospective audit of exudative age-related macular degeneration: 12-month outcomes in treatment-naive eyes. Invest Ophthalmol Vis Sci. 2013;54(8):5754-60.

27. Willis JR, Morse LS, Parke DWI, Rich WLI, Lum F. Treatment patterns for diabetic macular edema in the United States: analysis of the IRIS Registry (PA017). In: American Academy of Ophthalmology (AAO) Annual Meeting 2017. New Orleans. 2017.

28. Holekamp NM, Campbell J, Almony A, et al. Vision outcomes following anti-vascular endothelial growth factor treatment of diabetic macular edema in clinical practice. Am J Ophthalmol. 2018;191:83-91.

29. Hodzic-Hadzibegovic D, Sander BA, Monberg TJ, Larsen M, Lund-Andersen H. Diabetic macular oedema treated with intravitreal anti-vascular endothelial growth factor-2-4 years follow-up of visual acuity and retinal thickness in 566 patients following Danish national guidelines. Acta Ophthalmol (Copenh). 2018;96(3):267-78.

30. Stefanickova J, Cunha-Vaz J, Ulbig M et al. A noninterventional study to monitor patients with diabetic macular oedema starting treatment with ranibizumab (POLARIS). Acta ophthalmologica. 2018. doi: https://doi.org/10.1111/aos.13771.

31. Elman MJ, Bressler NM, Qin H, et al. Expanded 2-year follow-up of ranibizumab plus prompt or deferred laser or triamcinolone plus prompt laser for diabetic macular edema. Ophthalmology. 2011;118(4):609-14.

32. Tsai M-J, Hsieh Y-T, Peng Y-J. Real-life experience of ranibizumab for diabetic macular edema in Taiwan. Int Ophthalmol. 2018. https://doi.org/10.1007/ s10792-018-0970-7.

33. Holz FG, Tadayoni R, Beatty S, et al. Multi-country real-life experience of anti-vascular endothelial growth factor therapy for wet age-related macular degeneration. Br J Ophthalmol. 2015;99(2):220-6.

34. Brown DM, Nguyen QD, Marcus DM, et al. Longterm outcomes of ranibizumab therapy for diabetic macular edema: the 36-month results from two phase III trials: RISE and RIDE. Ophthalmology. 2013;120(10):2013-22. 